\title{
Optic Nerve Sheath Meningioma
}

National Cancer Institute

\section{Source}

National Cancer Institute. Optic Nerve Sheath Meningioma. NCI Thesaurus. Code C4538.

A meningioma that affects the sheath of the optic nerve. 